\title{
Estudando por vídeos: o Youtube como ferramenta de aprendizagem
}

\section{Studying by videos: Youtube as a learning tool}

\author{
DÉBORA DE LIMA VELHO JUNGES \\ Instituto Federal Catarinense (IFC)
}

\author{
AMANDA GATTI \\ Instituto Federal Catarinense (IFC)
}

\begin{abstract}
Resumo: $O$ artigo tem como objetivo verificar e analisar a utilização do Youtube como ferramenta de aprendizagem, com vistas a responder às seguintes questões: os alunos do Ensino Médio utilizam o Youtube como ferramenta de aprendizagem? Em caso afirmativo, como ocorre a prática de uso do Youtube como ferramenta de aprendizagem? A fundamentação teórica é vinculada a autores que abordam a temática das tecnologias educacionais. A metodologia se constituiu na aplicação de um questionário online com alunos que frequentavam o Ensino Médio Integrado. O exercício analítico identificou, dentre outros aspectos, as seguintes recorrências: a maioria dos jovens, além de utilizarem o Youtube no seu cotidiano, também faziam seu uso para fins de aprendizagem; em sua maioria, os participantes da pesquisa acreditavam que o acesso e a visualização de vídeos disponíveis no Youtube, relacionados à aprendizagem e à construção do conhecimento, influenciavam de forma positiva em seu desempenho escolar.
\end{abstract}

Palavras-chave: Youtube. Ferramenta de aprendizagem. Tecnologias educacionais.

\begin{abstract}
The paper aims to verify and analyze the use of Youtube as a learning tool, in order to answer the following questions: do high school students use Youtube as a learning tool? If so, how do they use Youtube as a learning tool? The theoretical basis is linked to authors who approach the subject of educational technologies. The methodology used was the application of an online questionnaire with students who attended the Integrated High School. The analytical exercise identified, among other aspects, the following recurrences: the vast majority of young people, besides using Youtube in their daily life, also used it for learning purposes; most of the participants in the research believed that the access and visualization of videos available on Youtube related to learning and the construction of knowledge had a positive influence on their school performance.
\end{abstract}

Keywords: Youtube. Learning tool. Educational technologies. 


\section{Introdução}

Atualmente, o uso das tecnologias é algo presente no cotidiano. Segundo uma pesquisa divulgada pelo Hootsuite e feita pelo Global Web Index - uma das maiores empresas de inteligência digital e análise de dados do mundo, que compilou informações obtidas até janeiro de 2017 -, o Brasil conta com 139.1 milhões de usuários da internet; e, apesar do Facebook e do Whatsapp serem as redes sociais mais faladas na mídia, o Youtube é a mais acessada no mundo, com $63 \%$ dos brasileiros conectados à internet fazendo uso regular da plataforma (HOOTSUITE, 2017).

O uso do Youtube, além de amplo e difundido, também é uma atividade diária para boa parte dos internautas. Segundo dados da mesma pesquisa citada anteriormente, $44 \%$ dos seus usuários assistem vídeos todos os dias, seja em dispositivos móveis, computadores e, até mesmo, Smart TV's.

O Youtube é uma plataforma de publicação de vídeos "que se utiliza da rede mundial de computadores para armazenar e expor os seus conteúdos. Não existe no mundo outro suporte técnico capaz de realizar essa tarefa para tantas pessoas e de uma forma tão acessível" (SERRANO, 2009, p. 9). A utilização do Youtube faz parte dos hábitos relacionados às mídias digitais de grande parte dos brasileiros e este artigo é fruto de um projeto de pesquisa realizado no ano de 2018 que procurou analisar como esse hábito impactava na aprendizagem dos alunos do Ensino Médio Integrado de uma instituição de ensino da rede federal no município brasileiro de Fraiburgo, estado de Santa Catarina (SC).

Dentre os objetivos específicos vinculados ao projeto de pesquisa, procurou-se verificar e analisar a utilização do Youtube como ferramenta de aprendizagem pelos estudantes da instituição citada, considerando os seguintes aspectos: motivação e finalidade para o uso; principais canais acessados; frequência de uso da plataforma; hábitos relacionados ao uso; impactos da utilização no contexto escolar; habilidade e competências relacionadas com o uso da plataforma. Neste contexto, este artigo tem como objetivo apresentar o resultado deste estudo, com vistas a responder às seguintes questões de pesquisa: os alunos utilizam o Youtube como ferramenta de aprendizagem? Em caso afirmativo, como ocorre a prática de uso do Youtube como ferramenta de aprendizagem?

\section{Fundamentação teórica}

Nas duas últimas décadas, o debate sobre o uso de tecnologias na educação cresceu. Impulsionado pela popularização das graduações e cursos técnicos na modalidade EAD, a discussão foi ampliada para o uso dessas tecnologias dentro de salas de aula na Educação Básica, levantando questionamentos sobre como ferramentas e plataformas digitais podem auxiliar professores e alunos que interagem presencialmente (SIBILIA, 2012). 
Essa discussão foi reforçada com a disseminação de conceitos como a "sala de aula invertida" ${ }^{1}$, o uso consciente da internet e todo o seu potencial para a educação (PACHECO, 2014). Isso se deu tanto no meio acadêmico, em pesquisas e publicações que analisam como é possível adaptar para essa nova realidade o uso das práticas pedagógicas já estabelecidas e como criar novas formas de ensinar (AMANTE, 2011; ARRUDA, 2013); quanto por uma iniciativa dos alunos, que desenvolveram maneiras próprias de buscar conhecimento (CANDAU, 2014).

O Youtube é uma plataforma de vídeos lançada em 2006, e comprada pela Google em 2009, por cerca de 1,5 bilhão de dólares. Desenvolvida, originalmente, para ser uma ferramenta de compartilhamento de vídeos pessoais, em uma época em que não existiam sites em que se pudesse realizar o upload desse tipo de arquivo e disponibilizar para várias pessoas a partir de um único ponto de acesso, o Youtube cresceu e se modificou, encontrando diversos públicos com gostos e necessidades distintas em sua evolução (BURGESS; GREEN, 2009).

Essa plataforma concentra bilhões de horas em clipes e vídeos musicais. Ela também é responsável por boa parte do consumo de entretenimento audiovisual no Brasil e, uma das maneiras em que isso se demonstra, é na crescente popularidade dos Youtubers - como são denominados os criadores de conteúdo em vídeo, que utilizam a plataforma como principal canal para os seus programas. São exemplos o coletivo humorístico "Porta dos Fundos", o canal "Manual do Mundo" e a vlogueira Kéfera.

O Youtube se distingue de outras plataformas de consumo de conteúdo por criar um espaço onde várias comunidades convivem e podem gerir seu espaço com certa liberdade. Inserida nessas diversas comunidades, temos as com foco na Educação. Elas se dividem, basicamente, entre duas vertentes: o "Edutretenimento", que, de acordo com Walldén (2004, apud AMÉRICO, 2007, p.72), "são programas que utilizam diversas mídias para incorporar mensagens educativas em formatos de entretenimento, ou seja, educam com métodos de entretenimento"; e os vídeos que buscam ensinar de uma maneira mais próxima às aulas tradicionais, se enquadrando no conceito mais comum de "videoaulas", que apresenta informações por meio de uma linguagem dinâmica em formato multimídia, combinando imagem, áudio, texto e movimento (KAMPFF, 2008). Para atingir seu público, as duas vertentes fazem uso dos recursos e do alcance do Youtube.

Conforme definição encontrada no próprio site do Youtube (2017), ela é uma plataforma que, entre outras funcionalidades, permite que os criadores de conteúdo utilizem as suas diversas ferramentas para publicar conteúdo audiovisual, para compreender melhor os hábitos do seu público e se comunicar por meio de ferramentas de comentário. Logo, por definição, o Youtube não é uma ferramenta, mas pode se tornar uma.

Em termos de uso, o Youtube pode ter vários fins. No sentido de distribuição de um conteúdo criado - funcionalidade primordial -, pode ser compreendido como uma plataforma, na qual o vídeo está hospedado, e, por meio da ferramenta de player de vídeo ali contida, outros usuários

\footnotetext{
1 o conceito da "sala de aula invertida" é considerado um contraponto ao ensino tido como tradicional, no qual o professor transmite informações para o aluno. "Basicamente, o conceito de sala de aula invertida é o seguinte: o que tradicionalmente é feito em sala de aula, agora é executado em casa, e o que tradicionalmente é feito como trabalho de casa, agora é realizado em sala de aula" (BERGMANN; SAMS, 2016, p.11).
} 
podem acessá-lo. Entretanto, o Youtube passa a ser uma ferramenta quando ganha um uso específico. No caso deste estudo, uma ferramenta de aprendizagem (CORREA; PEREIRA, 2016). Assim, o Youtube não foi criado, inicialmente, com o intuito de educar, mas os usuários aproveitaram seu potencial e seus recursos para tal objetivo.

A fim de compreendermos como os pesquisadores brasileiros têm abordado e compreendido o uso do Youtube como ferramenta de aprendizagem, recorremos ao Catálogo de Teses e Dissertações da Capes ${ }^{2}$. Por meio da busca neste Catálogo, elencamos três teses de doutoramento e seis dissertações de mestrado produzidas entre os anos de 2012 e 2016 que mais se aproximavam à temática desta pesquisa. Realizamos as leituras integrais de cada um dos estudos e destacamos os principais elementos, os quais apresentamos a seguir.

Um ponto interessante indicado pelas pesquisas de Batista (2014), Freire (2016), Boll (2013), Lopes (2014) e Matos (2016) é o papel de protagonismo assumido pelos jovens que produzem vídeos e os postam no Youtube. Para esses autores, os jovens que fazem uso do Youtube como uma ferramenta ou um instrumento de comunicação e de expressão, de articulação em redes colaborativas, de publicização de produções, de disseminação de conhecimentos, entre outras formas de uso, desenvolvem habilidades e competências relacionadas à autoria, à autonomia, à tomada de decisões, à criatividade, à criação de uma estética própria juvenil, além de participarem efetivamente da formação de um currículo cultural. Esses jovens aprendem, também, a lidar com a disponibilização de novos recursos e ferramentas tecnológicas com muito mais rapidez e demonstram estarem abertos para as novidades do cenário digital.

Ao analisarem os vídeos postados no Youtube que tinham como objetivo o ensino, seja o tema do vídeo inserido ou não no currículo escolar, os estudos desenvolvidos por Passos (2016), Oliveira (2016) e Silva (2016) evidenciam que há um cuidado com a linguagem utilizada nas narrativas produzidas a fim de que elas se aproximem do público-alvo dos vídeos. Ou seja, os Youtubers, ou aqueles que participam da produção dos vídeos postados no Youtube, procuram falar para e com o espectador, por meio de uma linguagem comum para ambos, de forma a trazer maior significado para os conteúdos que são abordados/ensinados, o que, na percepção dos autores dos estudos, torna a aprendizagem mais eficiente e eficaz.

No que diz respeito ao uso do Youtube como ferramenta de aprendizagem no espaço escolar, os jovens que participaram das pesquisas de Kamers (2013), Oliveira (2016) e Silva (2016) compreendem que a utilização efetiva do Youtube no contexto da sala de aula traria benefícios e qualificaria as aulas, uma vez que materiais audiovisuais tornam a explanação dos conteúdos mais atraente, por fazerem uso de uma linguagem mais próxima do cotidiano deles, diminuindo o distanciamento entre a escola e a cibercultura, na qual eles se encontram inseridos. Os jovens também se manifestaram a favor do uso do Youtube como ferramenta de aprendizagem pela possibilidade de se tornarem mais ativos na construção de seus conhecimentos com a criação de vídeos e postagens no Youtube, pois assim, além de participarem do processo educativo como protagonistas, eles também poderiam compartilhar com um maior número de pessoas os conhecimentos adquiridos com a sua participação nesse processo. No entanto, os jovens

\footnotetext{
${ }^{2}$ Capes - Coordenação de Aperfeiçoamento de Pessoal de Nível Superior.
} 
participantes das pesquisas afirmaram que o uso dos recursos midiáticos, em especial o Youtube, são pouco explorados no ambiente escolar, e, quando utilizados, servem apenas como material complementar para conteúdos abordados previamente pelo professor, o que subvaloriza o uso do Youtube como ferramenta de aprendizagem.

Na opinião dos professores participantes dos estudos de Kamers (2013), Oliveira (2016) e Silva (2016), o Youtube ainda é uma ferramenta pouco utilizada em sala de aula. Contudo, reconhecem que seu uso, de forma planejada e com intenções bem definidas, poderia contribuir para o processo de ensino e de aprendizagem, ao aproximar a escola às vivências dos alunos, tornando as aulas mais interessantes e estimulantes aos olhos dos educandos.

As teses e dissertações por nós analisadas ressaltam a importância de se procurar inserir, cada vez mais, o Youtube como ferramenta de aprendizagem no contexto das nossas escolas. Isso porque tanto alunos quanto professores participantes das pesquisas percebiam ganhos efetivos com a inserção dessa plataforma como ferramenta de auxílio na aprendizagem formal, seja como material de apoio para os docentes nas aulas, mas também dando voz e protagonismo para os jovens produzirem e compartilharem seus conhecimentos e suas produções em formato de vídeo no Youtube.

\section{Metodologia da pesquisa}

Conforme abordado na seção introdutória, o projeto de pesquisa que deu origem a este artigo teve como escopo verificar e analisar a utilização do Youtube como ferramenta de aprendizagem pelos alunos do Ensino Médio Integrado de uma instituição de ensino de Fraiburgo (SC). Neste sentido, a pesquisa se constituiu a partir de um processo de questionamentos acerca de um contexto específico, a fim de compreender o uso que os alunos do Ensino Médio Integrado desta instituição escolar faziam do Youtube como ferramenta de aprendizagem.

Dado que o objetivo desta pesquisa procurou investigar uma dada realidade sem características generalizantes, no que se refere ao tipo de procedimento para o processo de investigação, esta pesquisa se classificou como um estudo de caso. Um estudo de caso "visa conhecer em profundidade o como e o porquê de uma determinada situação que se supõe ser única em muitos aspectos, procurando descobrir o que há nela de mais essencial e característico" (FERREIRA, 2002, p. 33). Neste estudo de caso, a pesquisa se centrou na utilização do Youtube como ferramenta de aprendizagem pelos alunos que cursavam o Ensino Médio Integrado da instituição de ensino selecionada no ano de 2018.

Para alcançar o objetivo definido, um questionário foi aplicado com cada um dos alunos de todas as turmas do Ensino Médio, totalizando 184 respostas. A participação do discente foi condicionada ao preenchimento e à assinatura do Termo de Consentimento Livre e Esclarecido (TLCE) e do Termo de Assentimento Livre e Esclarecido (TALE). Também é relevante ressaltar que, considerada a natureza e as especificidades da pesquisa, a mesma foi submetida e aprovada pelo Comitê de Ética em Pesquisa com Seres Humanos do Instituto Federal Catarinense (CEPSH/IFC). 
Com relação à estrutura das perguntas, o questionário foi composto por uma questão aberta (na qual os respondentes ficaram livres para responderem com suas próprias palavras, sem limitar a escolha entre um rol de alternativas) e questões fechadas (na qual os respondentes optaram por uma das alternativas, ou por determinado número permitido de opções) (VIEIRA, 2009). O questionário foi elaborado na ferramenta denominada Google Forms, um aplicativo online e gratuito que se encontra no Google Docs, e os alunos participantes da pesquisa realizaram o preenchimento do questionário online nos Laboratórios de Informática da própria instituição de ensino.

Realizada a pesquisa de campo com a aplicação do questionário, os dados foram tabulados e foram gerados gráficos para melhor visualização dos resultados alcançados. Por fim, de posse da tabulação dos dados e dos gráficos produzidos, realizou-se a análise dos mesmos, tomando como base o referencial teórico do estudo, o qual será apresentado na próxima seção.

\section{Discussão dos resultados}

Como explicitado anteriormente, a aplicação do questionário contou com a participação de 184 estudantes do Ensino Médio Integrado da instituição selecionada como lócus da pesquisa. A partir da análise das respostas, foi possível identificar a utilização dos vídeos do Youtube como ferramenta de aprendizagem, bem como as características vinculadas ao seu uso nos percursos educacionais, os quais passaremos a apresentar nesta seção, balizadas pelos referenciais teóricos elencados neste estudo.

A fim de verificar a utilização do Youtube como ferramenta de aprendizagem pelos alunos participantes da pesquisa, primeiramente, questionamos se eles acessavam a plataforma. Dos 184 estudantes, 176 responderam "sim" à pergunta, o que representa 96\% do total, evidenciando que a maioria dos jovens daquela instituição acessavam o Youtube. Destes oito alunos que responderam "não" com relação ao acesso ao Youtube, metade elencou como principal razão para o não acesso a opção "não sei o que é o Youtube", enquanto que os outros quatro assinalaram a alternativa "não tenho interesse em acessar o Youtube".

Estes índices corroboram com os dados publicados no ano de 2017 na 2a edição do Youtube Insights, relatório que reúne os principais dados da plataforma (GOOGLE, 2017). Segundo a publicação oficial do Google, mensalmente no mundo, 1,5 bilhão de pessoas logadas na internet acessam o Youtube. No Brasil, $95 \%$ da população online acessa a plataforma pelo menos uma vez por mês. De acordo com Burgess e Green (2009, p. 21), "foi a combinação da popularidade em grande escala de determinados vídeos criados por usuários e o emprego do Youtube como meio de distribuição do conteúdo das empresas de mídia que agradou ao público".

Para aqueles que responderam "sim" no quesito acesso ao Youtube, foram realizados questionamentos vinculados diretamente aos hábitos de utilização da plataforma: sua frequência, dispositivo e local utilizados pelos usuários para o acesso.

Com relação ao primeiro hábito, foi realizada a seguinte pergunta: "Com que frequência na semana você acessa o Youtube?". A Tabela 1 apresenta os dados produzidos. 
Tabela 1 - Frequência de acesso ao Youtube

\begin{tabular}{|l|c|c|}
\hline $\begin{array}{l}\text { Com que frequência na semana você } \\
\text { acessa o Youtube? }\end{array}$ & Contagem & Porcentagem \\
\hline $2 \mathrm{~h}$ a $4 \mathrm{~h}$ & 38 & $22 \%$ \\
\hline $4 \mathrm{~h}$ a $8 \mathrm{~h}$ & 33 & $19 \%$ \\
\hline $8 \mathrm{~h}$ a $12 \mathrm{~h}$ & 27 & $15 \%$ \\
\hline Mais de $12 \mathrm{~h}$ & 60 & $34 \%$ \\
\hline Menos de $2 \mathrm{~h}$ & 18 & $10 \%$ \\
\hline Total & 176 & $100 \%$ \\
\hline
\end{tabular}

Fonte: Os autores, 2018.

Por meio da Tabela 1, é possível perceber que a grande maioria dos alunos participantes da pesquisa realizavam o acesso ao Youtube por mais de 12 horas semanais (34\%), enquanto aqueles que menos utilizavam a plataforma, ou seja, menos de 2 horas semanais, também representavam o menor número de alunos (no caso, 18 marcaram esta alternativa). Estes números confirmam o argumento de autores como Almeida et. al (2016) e Silva (2016), que observam que o uso do Youtube pelos jovens estudantes do Ensino Médio se tornou parte do seu cotidiano no contexto do ciberespaço.

A segunda questão, relacionada ao hábito dos alunos frente ao uso do Youtube, focou nos dispositivos utilizados por eles para o acesso à plataforma. Os dados do Youtube Insights indicam que $96 \%$ dos consumidores do Youtube acessam a internet todos os dias, principalmente através do smartphone (82\%) e do computador (66\%) (GOOGLE, 2017).

Os aparelhos celulares ou smartphones são um dos equipamentos tecnológicos mais comuns e de fácil acesso, inclusive para os jovens, que têm, na palma de suas mãos, centrais multimídias dotadas com uma série de funções. As possibilidades de conexão por meio de redes de amplo alcance, como é o caso do Youtube, e mediada por esses dispositivos móveis, "oferecem condições para que os usuários possam construir o seu próprio ambiente de comunicação e interação social" (AMORIM; CASTRO, 2010, p. 3).

Conforme pode ser observado na Tabela 2, a maioria dos alunos participantes da pesquisa utilizava como dispositivo principal o smartphone para acesso ao Youtube (121 alunos do total de 176), seguidos daqueles que acessam via desktop (32 alunos) e notebook (20 alunos). Apenas dois participantes assinalaram a Smart TV como dispositivo que mais utilizavam para acessar o Youtube, e apenas um indicou o uso do tablet. 
Tabela 2 - Dispositivo de acesso ao Youtube

\begin{tabular}{|l|c|c|}
\hline $\begin{array}{l}\text { Assinale o dispositivo que você mais } \\
\text { utiliza para acessar o Youtube: }\end{array}$ & Contagem & Porcentagem \\
\hline Desktop (computador de mesa) & 32 & $18 \%$ \\
\hline Notebook & 20 & $11 \%$ \\
\hline Smart TV & 2 & $1 \%$ \\
\hline Smartphone (celular) & 121 & $69 \%$ \\
\hline Tablet & 1 & $1 \%$ \\
\hline Total & 176 & $100 \%$ \\
\hline
\end{tabular}

Fonte: Os autores, 2018.

Por fim, com relação ao local em que ocorre este acesso, enquanto apenas $11 \%$ dos alunos indicaram a instituição de ensino como principal local de acesso ao Youtube, 89\%, ou seja, 157 participantes da pesquisa, assinalaram que o realizavam em suas moradias.

Considerando que o Youtube pode ser visto como um espaço democrático, do qual qualquer pessoa pode participar, tanto compartilhando vídeos, quanto acessando as postagens de outros usuários (PECHANSKY, 2016), se faz necessário procurar compreender como essa plataforma vem sendo utilizada pelos jovens como uma ferramenta de cunho educacional. Dado que esta pesquisa teve como foco o uso do Youtube como ferramenta de aprendizagem, as próximas discussões estão centradas nos dados produzidos diretamente relacionados a esta temática.

O Gráfico 1 apresenta os dados da primeira pergunta centrada em compreender se os 176 alunos participantes da pesquisa que acessavam o Youtube para fins diversos também utilizavam a plataforma como ferramenta para adquirir conhecimento.

Gráfico 1 - Acesso ao Youtube para aprender/buscar conhecimento

Você acessa o Youtube para aprender/buscar conhecimento?

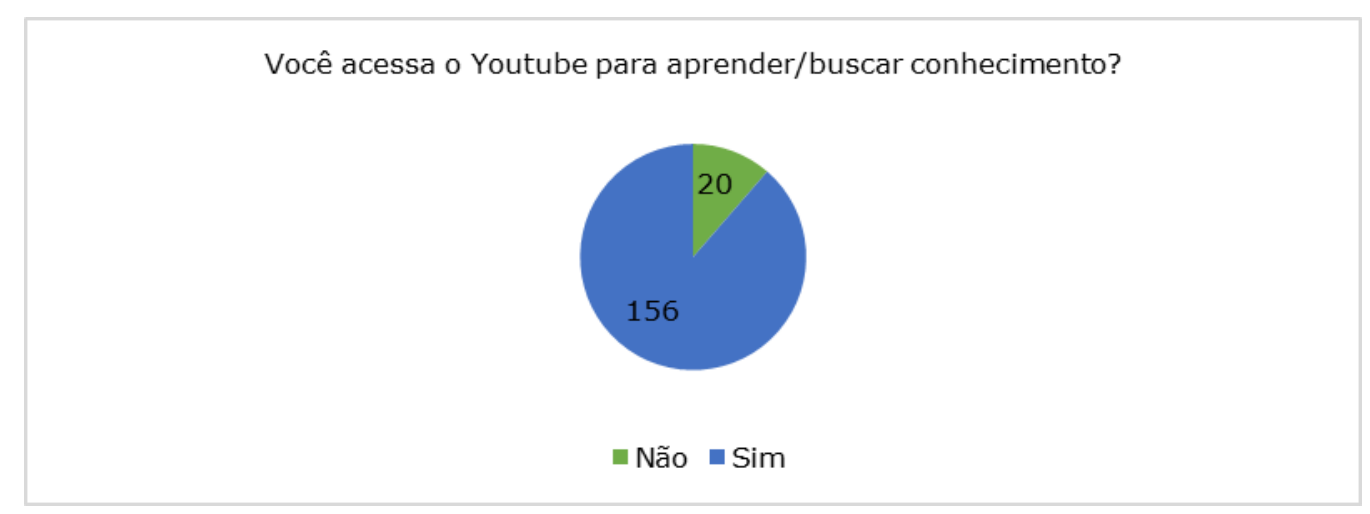

Fonte: Os autores, 2018.

Como pode ser observado, a maioria dos jovens além de utilizarem o Youtube no seu cotidiano para entretenimento, também faziam seu uso para fins de aprendizagem. Dos 176 participantes, 156 responderam "sim" ao questionamento, enquanto que apenas 20 responderam "não", representando $11 \%$ do total. Ou seja, $89 \%$ do total acessavam o Youtube para aprender/buscar 
conhecimento. Este significativo resultado, apresenta proximidades com outras pesquisas realizadas também no contexto brasileiro (KAMERS, 2013; OLIVEIRA, 2016; SILVA, 2016), as quais evidenciam que a linguagem audiovisual, presente nos vídeos postados no Youtube, pode ser considerada como um formato mediador de conhecimento para os alunos que frequentam a educação básica.

No estudo realizado por Silva (2016), por exemplo, dos 91 jovens que responderam a um questionário aplicado pelo pesquisador, $84 \%$ (76 alunos) responderam que assistiam a videoaulas no Youtube. Uma porcentagem muito próxima da que foi produzida em nossa pesquisa, o que nos leva, também, a concluir que o Youtube, "como ferramenta utilizada pelos alunos para estudar os conteúdos curriculares, foi apropriado pelos jovens investigados e já faz parte do processo de aprendizagem deste grupo" (SILVA, 2016, p. 61).

Para os 20 alunos que responderam "não" à questão de acesso ao Youtube para fins de aprendizagem, perguntamos também qual era o motivo que eles consideravam como principal para não fazerem uso do Youtube com vistas a aprender e/ou buscar por conhecimento. A maioria assinalou a opção "prefiro aprender/buscar conhecimento por meio de outras formas (como, por exemplo, livros, anotações pessoais, revistas)". Os resultados desta questão estão apresentados na Tabela 3.

Tabela 3 - Razões para não utilização do Youtube para aprender/buscar conhecimento

\begin{tabular}{|l|c|c|}
\hline $\begin{array}{l}\text { Qual a principal razão para não utilizar o Youtube para } \\
\text { aprender/buscar conhecimento? }\end{array}$ & Contagem & Porcentagem \\
\hline $\begin{array}{l}\text { Não consigo aprender/buscar conhecimento a partir de mídias digitais } \\
\text { ou vídeos }\end{array}$ & 1 & $5 \%$ \\
\hline $\begin{array}{l}\text { Não sabia que o Youtube poderia ser utilizado para aprender/buscar } \\
\text { conhecimento }\end{array}$ & 1 & $5 \%$ \\
\hline Não sei utilizar o Youtube para aprender/buscar conhecimento & 2 & $10 \%$ \\
\hline $\begin{array}{l}\text { Não tenho interesse em acessar o Youtube para aprender/buscar } \\
\text { conhecimento }\end{array}$ & 2 & $10 \%$ \\
\hline $\begin{array}{l}\text { Não tenho tempo para acessar o Youtube para aprender/buscar } \\
\text { conhecimento }\end{array}$ & 1 & $5 \%$ \\
\hline $\begin{array}{l}\text { Prefiro aprender/buscar conhecimento por meio de outras formas } \\
\text { (como, por exemplo, livros, anotações pessoais, revistas) }\end{array}$ & 13 & $65 \%$ \\
\hline Total & 20 & $100 \%$ \\
\hline
\end{tabular}

Fonte: Os autores, 2018

Com o objetivo de compreender melhor os hábitos relacionados ao uso do Youtube como ferramenta de aprendizagem dos 156 participantes da pesquisa que responderam "sim" à questão anterior, elencamos mais quatro questionamentos que consideramos pertinentes. 0 primeiro tratou da frequência semanal que os alunos despendiam quando do acesso ao Youtube com o propósito específico de aprender e/ou buscar conhecimento. 
Tabela 4 - Frequência semanal do uso do Youtube para aprender/buscar conhecimento

\begin{tabular}{|l|c|c|}
\hline $\begin{array}{l}\text { Com que frequência na semana você utiliza } \\
\text { o Youtube para aprender/buscar } \\
\text { conhecimento? }\end{array}$ & Contagem & Porcentagem \\
\hline $2 \mathrm{~h}$ a $4 \mathrm{~h}$ & 47 & $30 \%$ \\
\hline $4 \mathrm{~h}$ a $8 \mathrm{~h}$ & 29 & $19 \%$ \\
\hline $8 \mathrm{~h}$ a $12 \mathrm{~h}$ & 7 & $4 \%$ \\
\hline Mais de $12 \mathrm{~h}$ & 8 & $5 \%$ \\
\hline Menos de $2 \mathrm{~h}$ & 65 & $42 \%$ \\
\hline Total & 156 & $100 \%$ \\
\hline
\end{tabular}

Fonte: Os autores, 2018

Os dados da Tabela 4 mostram que a maioria dos alunos acessavam o Youtube para fins ligados à educação por período menor que duas horas semanais (65 marcaram esta alternativa, representando $42 \%$ do total), seguido daqueles que passavam de 2 a 4 horas (47, 30\% do total) e de 4 a 8 horas $(29,19 \%$ do total) por semana nesta atividade. Em menor quantidade, 7 participantes indicaram passar de 8 a 12 horas semanais e 8 passavam mais de 12 horas acessando vídeos com objetivo educacional.

Diante destes números, podemos perceber que quase $50 \%$ dos alunos acessavam o Youtube para aprender e/ou buscar conhecimento de 2 a 8 horas semanalmente, um período de tempo considerável, tendo em vista a grande quantidade de estímulos visuais que os usuários da internet recebem ao acessarem as páginas do Youtube. Até porque, como alerta Kamers (2012, p. 130), "na rede há uma facilidade muito grande para navegar por uma quantidade gigante de informações e essa facilidade, de certa forma, deixa o jovem com uma certa resistência de se aprofundar em determinado assunto".

A pergunta seguinte focou na percepção do estudante sobre o seu rendimento ao fazer uso do Youtube: "utilizando o Youtube para aprender/buscar conhecimento, você acredita que isso tem um resultado positivo no seu desempenho escolar?". 98\% dos participantes da pesquisa responderam "sim" a esta questão. Em números absolutos, 153 alunos acreditam que o acesso e a visualização de vídeos disponíveis no Youtube relacionados à aprendizagem e à construção do conhecimento influenciam de forma positiva em seu desempenho escolar.

Ao considerarem o Youtube como uma ferramenta capaz de qualificar o seu próprio processo de ensino-aprendizagem, é possível inferir que "os jovens alteraram a sua forma de aprender com a utilização que fazem das videoaulas, e outros recursos digitais, ao longo do processo educacional" (SILVA, 2016, p. 71). No caso desta pesquisa, os alunos que responderam "sim" à questão da percepção do seu próprio desempenho escolar com o uso que fazem do Youtube, evidenciam que esta prática, para além de uma escolha pessoal, repercute nos processos educacionais inseridos no espaço escolar, promove uma alteração na dinâmica da sala de aula (tendo em vista um provável desempenho melhor dos alunos nos conteúdos curriculares) e 
demonstra que, para esse grupo de jovens, a web também se constitui como um espaço que promove a aprendizagem e a construção do conhecimento. "Neste sentido, a íntima relação entre a cibercultura e a cultura juvenil aproxima a juventude das formas de aprender intimamente vinculadas às tecnologias digitais" (SILVA, 2016, p. 69).

Ao serem questionados sobre as principais razões que os levavam a utilizar o Youtube como ferramenta para aprender e/ou buscar conhecimento, os 156 alunos puderam optar por marcar múltiplas opções de respostas. Os dados produzidos estão contidos na Tabela 5.

Tabela 5 - Principais razões para utilização do Youtube para aprender/buscar conhecimento

\begin{tabular}{|l|c|c|}
\hline $\begin{array}{l}\text { Qual(is) a(s) principal(is) razão(ões) que te leva(m) a utilizar o } \\
\text { Youtube para aprender/buscar conhecimento? (múltiplas } \\
\text { alternativas) }\end{array}$ & Contagem & Porcentagem \\
\hline Gosto de aprender/buscar conhecimento por conta própria & 46 & $29 \%$ \\
\hline Aprendo melhor assistindo vídeos & 76 & $49 \%$ \\
\hline Facilidade no acesso aos conhecimentos & 44 & $28 \%$ \\
\hline Para compreender melhor um conteúdo estudado em sala de aula & 67 & $43 \%$ \\
\hline $\begin{array}{l}\text { Como forma de se preparar para avaliações na própria instituição de } \\
\text { ensino (provas, testes, trabalhos) }\end{array}$ & 75 & $27 \%$ \\
\hline $\begin{array}{l}\text { Como forma de se preparar para avaliações externas, como Vestibular } \\
\text { e ENEM }\end{array}$ & 42 & $29 \%$ \\
\hline $\begin{array}{l}\text { Os vídeos utilizam uma linguagem mais acessível para compreensão } \\
\text { dos conhecimentos }\end{array}$ & 45 & $24 \%$ \\
\hline $\begin{array}{l}\text { Aprendo melhor com a visualização de imagens, fotos, ilustrações } \\
\text { inseridas nos vídeos }\end{array}$ & 38 & \\
\hline Total & 156 & \\
\hline
\end{tabular}

Fonte: Os autores, 2018

Para a maioria dos participantes da pesquisa, a utilização do Youtube como ferramenta de aprendizagem está relacionada a dois motivos principais: a percepção de que se aprende melhor assistindo vídeos (49\% assinalaram esta alternativa, ou seja, 76 alunos) e que esta é uma forma de se preparar para avaliações (provas, testes, trabalhos) a serem realizadas na própria instituição escolar (48\% assinalaram esta opção, totalizando 75 alunos). Na sequência, a alternativa mais utilizada diz respeito à possibilidade de vir a compreender melhor um conteúdo estudado em sala de aula, com 67 alunos assinalando esta resposta. Esses números, especialmente os dois últimos, reforçam os argumentos discutidos anteriormente, de que, mais do que uma escolha meramente individual de busca por um processo de aprendizagem nãoconvencional, o uso do Youtube impacta no contexto escolar, direta e indiretamente.

A escola, como espaço privilegiado para a promoção dos processos de ensino e de aprendizagem, no qual o conhecimento circula entre todos os envolvidos nestes processos, é impactada pelas diferentes tecnologias de informação e comunicação disponíveis para uso pelos 
alunos. Isto porque, a instituição escolar "deixou de ser o único lugar de legitimação de saber, pois existe uma multiplicidade de saberes que circulam por outros canais, difusos, descentralizados" (MARTÍN-BARBERO, 2008, p. 126), como é o caso do Youtube.

Praticamente metade dos participantes da pesquisa acreditavam que aprendiam melhor ao assistirem vídeos no Youtube. Além disso, os vídeos utilizam uma linguagem mais acessível para compreensão dos conhecimentos ( $29 \%$ assinalaram esta alternativa) e se aprende melhor com a visualização de imagens, fotos, ilustrações inseridas nos vídeos (24\% marcaram esta opção), segundo a percepção dos alunos que responderam ao questionário. Estas constatações corroboram com as afirmações de diversos autores, tais como Pechansky (2016) e Almeida et. al (2016), de que se faz necessário e urgente considerar a inserção de ferramentas audiovisuais em sala de aula como uma prática pensada e planejada por parte do corpo docente das instituições. Isso em razão de que as mídias, como mediadoras e facilitadoras do processo de ensino e de aprendizagem: ajudam a melhorar a comunicação escola-aluno-mundo (KAMERS, 2013); aproximam do aluno a possibilidade de alcançar o sucesso escolar (SILVA, 2016); permitem ao professor estar mais próximo da linguagem do aluno (BISPO; BARROS, 2016); dentre outros aspectos.

Retornando aos dados produzidos no questionário, também solicitamos que os alunos participantes da pesquisa escrevessem os principais canais do Youtube que acessavam com vistas a aprender e/ou buscar conhecimento. Como não havíamos estabelecido um número mínimo ou máximo de canais a serem listados por cada um dos estudantes, um número considerável de canais foi citado.

Contabilizamos os canais "Biologia Total com prof. Jubilut" (30 indicações), "Nostalgia" (27), "Aula De" (23), "Descomplica" (21) "Você Sabia" (20), "Ferretto Matemática" (19), "Professor Ricardo Annes" (18), "Geografia Irada" (18) e "Me Salva" (18) como os mais acessados pelos alunos, e famosos entre eles. Dentre os canais citados, nos chamaram a atenção a presença de dois canais de professores que lecionavam ou que haviam lecionado para alguns dos alunos que participaram do preenchimento do questionário, demonstrando que certos professores do próprio lócus da pesquisa já utilizavam o Youtube como ferramenta de aprendizagem e divulgavam seus canais entre os estudantes. No entanto, cabe ressaltar que, como foge do escopo desta pesquisa, não realizamos a análise dos canais mais citados.

Por fim, a última pergunta do questionário foi aplicada para todos os 184 participantes da pesquisa (tanto para aqueles que assinalaram acessar o Youtube, quanto para aqueles que não faziam uso da plataforma): "você gostaria que o Youtube fosse utilizado pelos seus professores como uma ferramenta de aprendizagem nas aulas?". 163 alunos responderam "sim" ao questionamento, o que representa $89 \%$ do total, enquanto que 21 estudantes assinalaram que não gostariam que o Youtube fosse utilizado pelos seus professores como ferramenta de aprendizagem, contabilizando $11 \%$.

Este último dado da pesquisa é interessante por dois diferentes aspectos. Primeiramente, por evidenciar que grande parte dos alunos acreditavam que o Youtube poderia ser uma ferramenta didática útil aplicada pelos professores no processo de ensino e de aprendizagem, o que confirma os apontamentos realizados ao longo desta seção. 
Um segundo aspecto é a percepção que, dentre os alunos que responderam de forma afirmativa a esta última questão do questionário, provavelmente assinalaram esta alternativa alunos que não acessavam o Youtube (que somavam oito participantes) e/ou alunos de acessavam o Youtube, mas não para aprender ou buscar conhecimento (que totalizavam 20 alunos). Isto porque, conforme apresentado anteriormente, 156 alunos participantes da pesquisa utilizavam a plataforma como ferramenta para adquirir conhecimento, logo, se 163 alunos responderam positivamente à questão do uso do Youtube pelos seus professores, alguns dos que não acessavam o Youtube ou que não o utilizavam para fins educacionais deveriam querer que esse recurso midiático fosse inserido nas aulas ministradas pela instituição de ensino de que faziam parte. Esta constatação reforça o alcance que o Youtube tem entre os jovens, e que estes o vêem não apenas como uma plataforma de entretenimento, divulgação de informações e compartilhamento de vídeos, mas também como uma ferramenta de aprendizagem e de construção do conhecimento.

\section{Considerações finais}

O Youtube, para além de um site de compartilhamento de vídeos, no qual os usuários são estimulados a se comunicarem por meio de recursos disponibilizados pela própria plataforma, também passou a ser considerada uma ferramenta relevante nos processos de ensino e de aprendizagem. "Este site tornou-se fascinante, pois, expor a opinião, produzir informação, debates, conteúdos científicos, educacionais, humorístico entre outros [...] o torna útil para a compreensão das relações sociais, evolução das tecnologias e das mídias, auxiliando na práxis escolar" (ALMEIDA et. al., 2016, p.4).

Relevante no contexto educacional, as tecnologias de informação e comunicação estão presentes no cotidiano de todos, inclusive na vida dos alunos, e são instrumentos produtivos de pesquisa e disseminação do conhecimento. No caso deste estudo, nos questionamos quanto à utilização do Youtube como ferramenta de aprendizagem pelos alunos que frequentavam o Ensino Médio Integrado da instituição de ensino selecionada como lócus da pesquisa. Tendo como base este questionamento, realizamos a aplicação de um questionário on-line, que teve como objetivo analisar a utilização do Youtube como ferramenta de aprendizagem por estes alunos, considerando os seguintes aspectos: motivação e finalidade para o uso; principais canais acessados; frequência de uso da plataforma; hábitos e gatilhos no uso; impactos da utilização no contexto escolar; habilidade e competências relacionadas com o uso da plataforma.

Os dados da pesquisa, apresentados na seção anterior, evidenciaram que a maioria dos jovens além de utilizarem o Youtube no seu cotidiano, também faziam seu uso para fins de aprendizagem; e que, em sua maioria, os participantes da pesquisa acreditavam que o acesso e a visualização de vídeos disponíveis no Youtube, relacionados à aprendizagem e à construção do conhecimento, influenciavam de forma positiva em seu desempenho escolar. Tais constatações corroboram com outros estudos já realizados e discutidos neste artigo (KAMERS, 2013; OLIVEIRA, 2016; e SILVA, 2016), além de servirem como justificativa para a posição de diversos estudiosos em educação que defendem a ampliação consciente do Youtube e de outras 
ferramentas midiáticas e digitais no contexto da sala de aula (PECHANSKY, 2016; ALMEIDA et. al, 2016; CORREA, PEREIRA, 2016).

A sociedade está utilizando cada vez mais a interação social em um contexto midiático. Por isso, é necessário que a escola, como uma das instituições que promovem a interação entre pessoas, acompanhe esse desenvolvimento. As linguagens multimídia fazem parte do cotidiano de todos e repercutem no contexto das instituições escolares. Acreditamos que, diante de uma sociedade que valoriza e utiliza as mais diversas tecnologias, a educação e, mais especificamente, o ambiente escolar não deveriam permanecer indiferentes ao uso destes recursos que podem contribuir para a qualificação dos processos de ensino e de aprendizagem. Ao contrário, a compreensão deste fenômeno deveria instigar ações que procurassem inserir, cada vez mais, o Youtube e outras tecnologias de informação e comunicação como ferramentas pedagógicas. Isto porque, o uso intencional e criterioso dessas ferramentas tende a tornar as aulas mais criativas e interessantes, facilitando o processo de ensino e auxiliando na compreensão de conteúdos.

\section{Referências}

ALMEIDA, I. [et. al.]. Tecnologias e educação: o uso do Youtube na sala de aula. In: Congresso Nacional de Educação. Anais. Campina Grande, n. 2., p. 1-12, 2016.

AMANTE, L. Tecnologias digitais, escola e aprendizagem. Ensino em Re-Vista. v. 18, n. 2, p. 221-404, 2011.

AMÉRICO. M. A Produção de Conteúdos Audiovisuais Educacionais Interativos para TV Digital. Anais do INTERCOM 2007 - XXX Congresso Brasileiro de Ciências da Comunicação. Santos: ago./ set. 2007.

AMORIM, P.; CASTRO, D. Mídias digitais: uma nova ambiência para a comunicação móvel. Encontro de História da Mídia da Região Norte. Anais. Palmas, n. 1, p. 1-11, out. 2010.

ARRUDA, E. Ensino e aprendizagem na sociedade do entretenimento: desafios para a formação docente. Educação (PUCRS. Impresso). v. 36, p. 232-239, 2013.

BATISTA, L. Jovens Youtubers: Processos de Autoria e Aprendizagens Contemporâneas. Dissertação (Mestrado em Educação). Universidade Federal do Estado do Rio de Janeiro, Rio de Janeiro, RJ, 2014.

BISPO, L; BARROS, K. Vídeos do Youtube como recurso didático para o ensino de história. Atos de Pesquisa em Educação. Blumenau, v. 11, n. 3, p. 856-868, set./dez. 2016.

BOLL, C. A Enunciação Estética Juvenil em Videos Escolares no Youtube. Tese (Doutorado em Educação). Universidade Federal do Rio Grande do Sul, Porto Alegre, RS, 2013.

BURGESS, J.; GREEN, J. Youtube e a revolução digital: como o maior fenômeno da cultura participativa transformou a mídia e a sociedade. São Paulo: Aleph, 2009.

CANDAU, V. Educação intercultural: entre afirmações e desafios. In: MOREIRA, A.; CANDAU, V. (Orgs.) Currículos, disciplinas escolares e culturas. Petrópolis: Editora Vozes, 2014.

CAPES. Catálogo de Teses e Dissertações da Capes. Disponível em:

<http://catalogodeteses.capes.gov.br/catalogo-teses/\#!/>. Acesso em: 02 mar. 2018.

CORREA, A.; PEREIRA, H. O Youtube como ferramenta pedagógica em sala de aula: uma prática de letramento. Revista de Pesquisa Interdisciplinar. Cajazeiras, v. 1, Ed. Especial, p. 381 - 389, set./dez. 2016. 
FERREIRA, N. As pesquisas denominadas "estado da arte". Educação e Sociedade, Campinas, v. 23, n. 79, p. 257-272, ago. 2002.

FREIRE, J. Produzir comunicação na cibercultura: coisa de criança! Tese (Doutorado em Educação). Universidade do Estado do Rio de Janeiro, Rio de Janeiro, RJ, 2016.

GOOGLE. Youtube Insights 2017. Disponível em: <https://www.thinkwithgoogle.com/intl/ptbr/youtubeinsights/2017/introducao/>. Acesso em: 29 out. 2018.

HOOTSUITE. Hootsuite's Social Media Trends for 2017. Disponível em: <https://hootsuite.com/pt/pages/ landing/2017-social-trends>. Acesso em: 27 out. 2018.

KAMERS, N. O Youtube como Ferramenta Pedagógica no Ensino de Física. Dissertação (Mestrado em Educação). Universidade do Estado de Santa Catarina, Florianópolis, SC, 2013.

KAMERS, N. O Youtube como ferramenta pedagógica para o ensino de física. Revista Electrónica de Investigación y Docencia (REID). Espanha, v. 7, p. 127-139, jan. 2012.

KAMPFF, A. Tecnologia da Informação e Comunicação na Educação. Curitiba: IESDE Brasil S.A., 2008.

LOPES, A. O olhar do aluno mediado pelas tecnologias digitais: o youtube e a (re)definição da relação pedagógica. Dissertação (Mestrado em Educação). Universidade Federal de São Carlos, São Carlos, SP, 2014.

MARTÍN-BARBERO, J. Dos meios às mediações: comunicação, cultura e hegemonia. 5. ed. Rio de Janeiro: UFRJ, 2008.

MATOS, R. Estudantes equipados: as representações sociais da escola pública em audiovisuais postados no Youtube. Tese (Doutorado em Educação). Pontifícia Universidade Católica do Rio de Janeiro, Rio de Janeiro, RJ, 2016.

OLIVEIRA, J. Educação Histórica e Aprendizagem da "História Difícil" em Vídeos de Youtube. Dissertação (Mestrado em Educação). Universidade Federal do Paraná, Curitiba, PR, 2016.

PACHECO, J. Sala de aula invertida. Revista Educação. v. 205, mai. 2014.

PASSOS, G. Aperte o play e assista! Youtube, a sala de aula dos gamers?. Dissertação (Mestrado em Educação). Universidade Federal de Santa Catarina, Florianópolis, SC, 2016.

PECHANSKY, R. O YouTube como plataforma educacional: reflexões acerca do canal Me Salva. XVII Congresso de Ciências da Comunicação na Região Sul. Anais. Porto Alegre, p. 1-13, mai. 2016.

SERRANO, P. Cognição e interacionalidade através do Youtube. Biblioteca On-line de Ciências da Comunicação. v. 1, p. 04-29, 2009.

SIBILIA, P. A escola no mundo hiperconectado: Redes em vez de muros? Matrizes. Ano 5, n. 2, p. 195-211, 2012.

SILVA, M. Youtube, juventude e escola em conexão: a produção da aprendizagem ciborgue. Dissertação (Mestrado em Educação). Universidade Federal de Minas Gerais, Belo Horizonte, MG, 2016.

YOUTUBE. Disponível em: <https://creatoracademy.youtube.com/page/course/platform?hl=pt-BR>. Acesso em: 06 out. 2018.

Recebido em dezembro de 2018.

Aprovado para publicação em julho de 2019.

\section{Débora de Lima Velho Junges}

Doutora em Educação - Universidade do Vale do Rio dos Sinos - UNISINOS, Técnica em Assuntos Educacionais - Instituto Federal Catarinense - IFC, Brasil, deborajunges@gmail.com 


\section{Amanda Gatti}

Bolsista de Iniciação Científica - Instituto Federal Catarinense - IFC, Brasil, amanda.2017317077@gmail.com 